\title{
Yesterday masked, today modified; what do mycotoxins bring next?
}

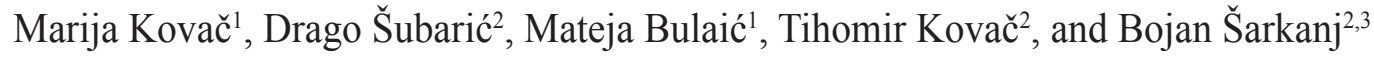 \\ Inspecto Ltd., Đakovo', Josip Juraj Strossmayer University of Osijek, Faculty of Food Technology Osijek², Department \\ of Food Technology, University North, Koprivnica ${ }^{3}$, Croatia
}

[Received in February 2018; Similarity Check in February 2018; Accepted in May 2018]

Mycotoxins are secondary metabolites produced by toxigenic fungi in crops worldwide. In (micro)organisms such as plants, fungi, bacteria, or animals they may be further metabolised and modified, but this is also true for food processing, which may lead to a wide range of masked mycotoxin forms. These often remain undetected by analytical methods and are the culprits for underestimates in risk assessments. Furthermore, once ingested, modified mycotoxins can convert back to their parent forms. This concern has raised the need for analytical methods that can detect and quantify modified mycotoxins as essential for accurate risk assessment. The promising answer is liquid chromatography-mass spectrometry. New masked mycotoxin forms are now successfully detected by iontrap, time-of-flight, or high-resolution orbitrap mass spectrometers. However, the toxicological relevance of modified mycotoxins has not been fully clarified.

KEY WORDS: LC-MS/MS; LC-HRMS; secondary fungal metabolites; toxicology

Global concern about the contamination of agricultural commodities with mycotoxins, secondary fungal metabolites, has increased over the last years (1-3). Although the total number of mycotoxins is unknown, it is estimated that there are thousands of fungal secondary metabolites, but only a few hundred have been documented as toxic at low amounts. This low-amount toxicity is what sets mycotoxins apart from other secondary metabolites, such as ethanol. Ethanol is not a mycotoxin, even though it is a secondary fungal metabolite (4). The United Nations Food and Agriculture Organization (FAO) has estimated that about $25 \%$ of the crops worldwide are contaminated with mycotoxins $(1,5)$. Recent reports, however, indicate that the contamination of commodities (cereals and feed) is much higher: roughly $80 \%(1,5,6)$. These figures are expected to rise with the use of more sensitive detection methods and equipment, which will increase the mycotoxin database and standards.

The most important fungal genera producing mycotoxins are Aspergillus, Fusarium, Alternaria, and Penicillium (6) (Figure 1) and the most relevant mycotoxins for animal and human health worldwide are aflatoxins B1 (AFT B1), B2 (AFT B2), G1 (AFT G1), G2 (AFT G2), and M1 (AFT M1), ochratoxin A (OTA), zearalenone (ZEN), deoxynivalenol (DON), T-2 and HT-2 toxins, fumonisins B1 (FB1) and B2 (FB2), and patulin. The European Union has regulated their maximum levels in certain foodstuffs in the Commission

Correspondence to: Tihomir Kovač, Josip Juraj Strossmayer University of Osijek, Faculty of Food Technology, Franje Kuhača 18, 31107 Osijek, E-mail: tihomir.kovac@ptfos.hr
Regulation (EC) No. 1881/2006 (8) and the Commission Recommendation 2013/165/EU (9).

Toxicity syndromes resulting from the intake of mycotoxins by humans and animals are known as mycotoxicoses (10). In some cases, the manifested clinical symptoms of a mycotoxicosis are significantly greater than expected from food or feed contamination level. This has led to the discovery of the so-called masked mycotoxins, which, as their name implies, escape detection by conventional analytical methods, initially developed for specific mycotoxins $(7,11)$.

As the term masked mycotoxins has often been used for all conjugated mycotoxins generated by or present in plants, animals, fungi, and food processing, Rychlik et al. (12) proposed a systematic four-tier hierarchy displayed in Figure 2 (11-13). The first tier distinguishes free mycotoxins from matrix-associated mycotoxins and mycotoxins with modified basic chemical structure. The second tier further distinguishes biologically modified mycotoxins from the chemically modified ones. The third tier includes biologically modified compounds that are divided into functionalised, conjugated, and differently modified mycotoxins. Finally, the fourth tier, which consists of the biologically conjugated mycotoxins, is divided into plant, animal, and fungal conjugates (12). This system, however, is sometimes difficult to use, since some masked forms can be synthesised by both fungi and plants (e.g. zearalenone sulphate) (14).

The presence of modified mycotoxins in cereals had long been speculated, until Schneweis et al. (15) 
a)
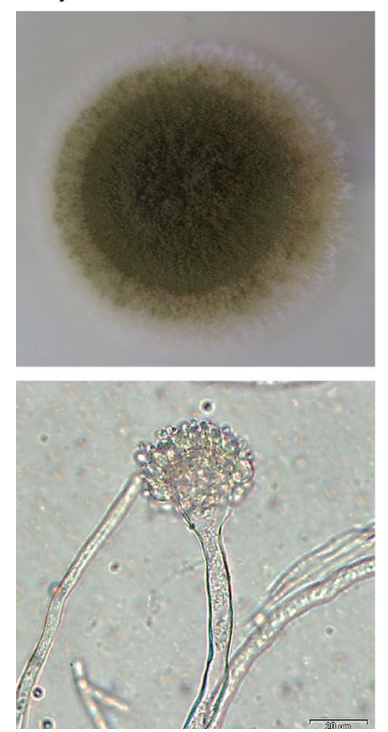

b)
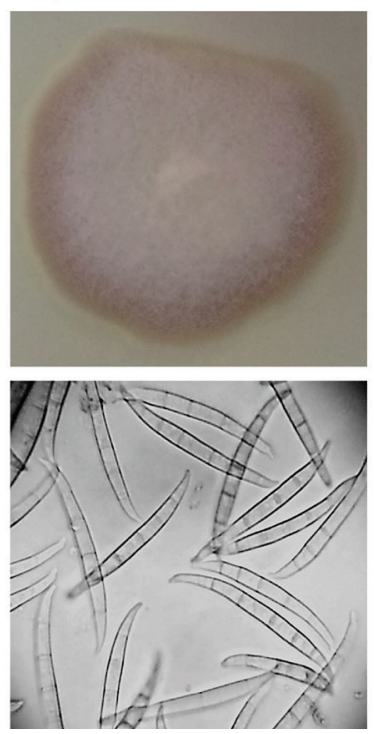

c)
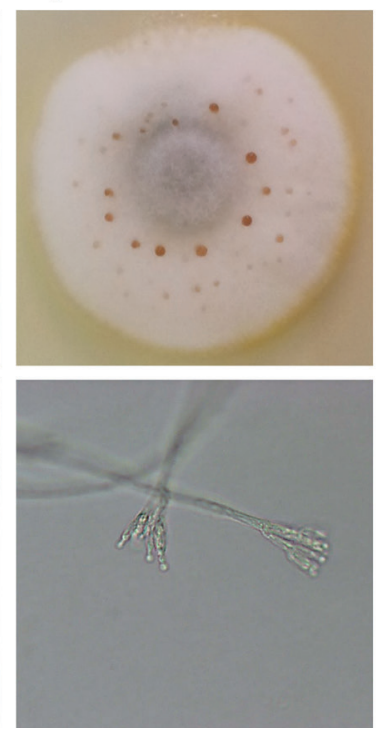

d)

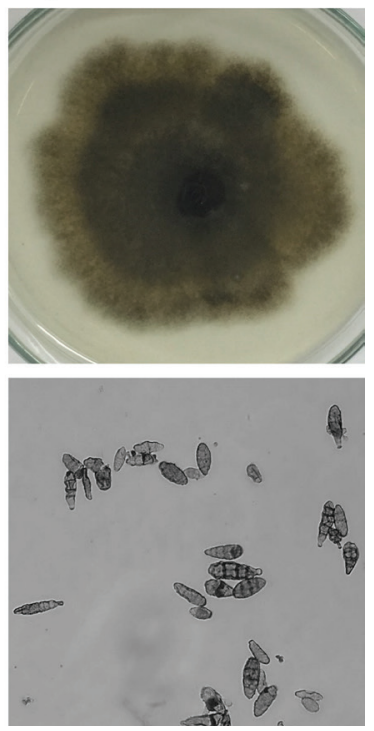

Figure 1 The most important mycotoxin-producing fungi with their respective conidia microphotography: a) Aspergillus flavus (NRRL 3251); b) Fusarium verticilioides (CBS 119.825); c) Penicillium expansum (CBS 325.48); and d) Alternaria alternata (wt) grown on PDA agar for 7 days

demonstrated modified zearalenone-14-glucoside (ZEN14Glc) (Figure 3) in naturally contaminated wheat. Three years later, Berthiller et al. (16) reported another mycotoxin glucoside in naturally infected cereals, deoxynivalenol-3-glucoside (DON3Glc) (Figure 3). Years that followed witnessed new evidence about mycotoxins masked/modified by technological processes, especially in cereal-based products. Mechanical or thermal processing was shown to induce mycotoxin reactions with macromolecules such as polysaccharides and proteins or decomposition of their modified form and the release of a free mycotoxin $(17,18)$.

Recent research using advanced techniques based on mass spectrometry (MS) has detected and confirmed a number of modified mycotoxin derivatives. The most powerful technique among them is liquid chromatography coupled to orbitrap high resolution mass spectrometry (LCHRMS), which has pointed to a whole new range of possibly masked mycotoxins (19) that have later been confirmed by triple quadrupole (QqQ) mass spectrometry analyser in real wheat (20) and human urine samples (21). Beside these, liquid chromatography/tandem mass spectrometry (LC-MS/ MS) has confirmed the existence of theoretical molecules such as DON-glutathione conjugates in cereals, first synthesised and characterised by nuclear magnetic resonance spectroscopy $(22,23)$.

Despite these discoveries, there are still no directives, regulations, or recommendations regarding modified mycotoxins $(11,24)$. The European Food Safety Authority (EFSA) has emphasised the need for more occurrence data on modified mycotoxins in food and feed in order to assess exposure and the effects on human and animal health (13, $25)$. In addition, the latest zearalenone (ZEN) risk assessment (26) included the modified forms of ZEN and confirmed even higher toxicity than that of the parent mycotoxin. The aim of this review is to describe the current knowledge about common modified mycotoxins, their formation, occurrence, analytical aspects, and toxicology.

\section{FORMATION OF MODIFIED MYCOTOXINS}

Biological modifications of mycotoxins through conjugation by plants or fungi as well as modifications caused by food processing can be the main contributors to food and feed contamination levels (11). Table 1 gives an overview of the most common modified mycotoxins and their profile, including the matrices in which they usually occur.

\section{Conjugation by plant}

To protect themselves from xenobiotics such as mycotoxins, plants trigger a detoxification process $(7,11)$ consisting of the following three stages: transformation, solubilisation, and compartmentalisation. In the first stage, xenobiotics undergo hydrolysis, reduction or oxidation, which form reactive groups in the xenobiotic structure. This stage is typical for lipophilic compounds, which become more hydrophilic. When foreign substances, such as the hydrophilic ones, already possess reactive groups, detoxification skips the first stage and immediately starts with the second. In the second stage, xenobiotics are conjugated with endogenous molecules such as sugars, sulphates, or amino acids. Formed conjugates are more polar than the original xenobiotic molecule, which facilitates their compartmentalisation (the third stage) (11). 


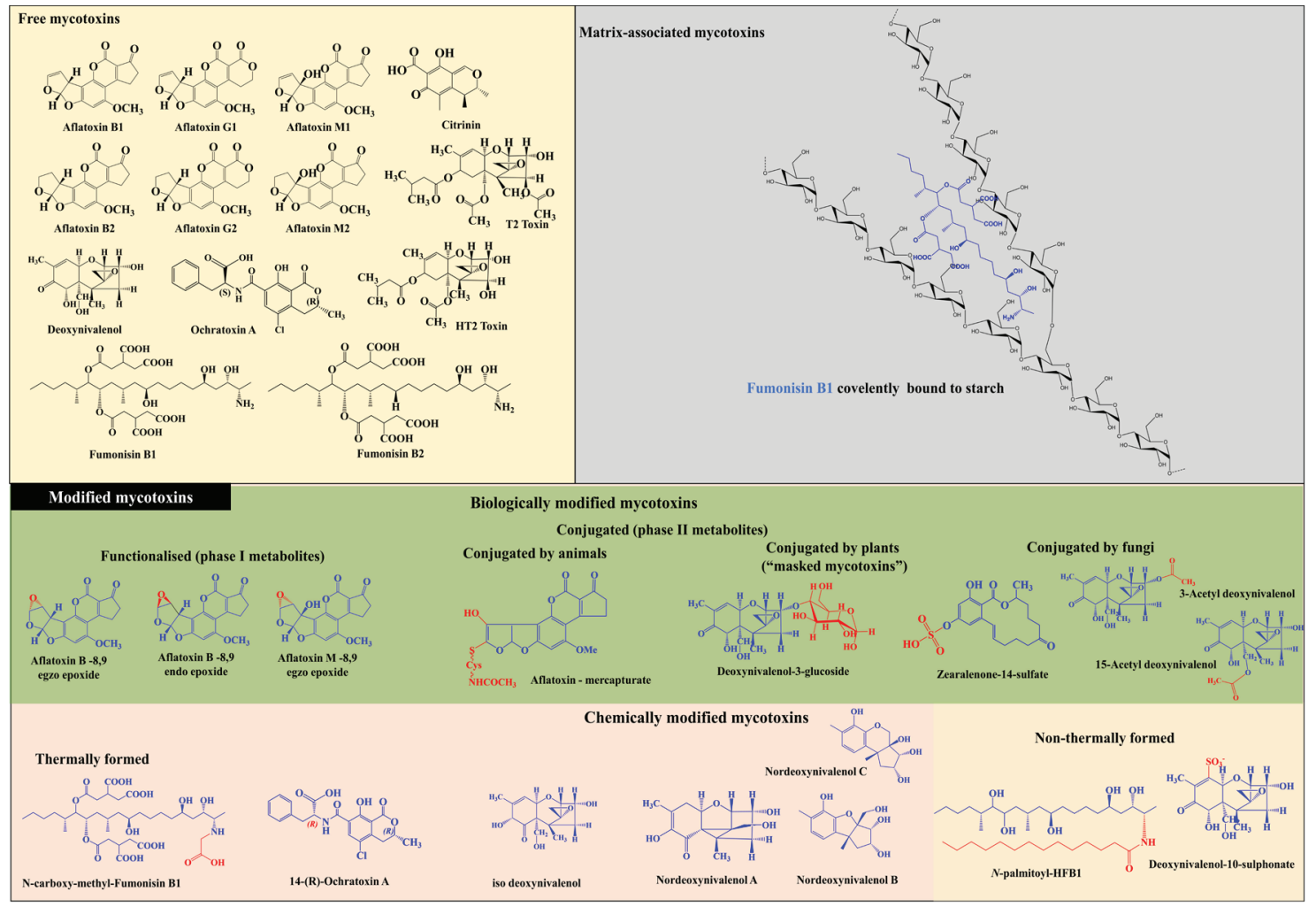

Figure 2 Mycotoxin systematisation proposed by Rychlik et al. (12)

This prevents harmful interaction between conjugated xenobiotics and plant components. Even so, these conjugates persist in plants long enough to have important toxicological consequences for their consumers. It has been suggested that some plant conjugates undergo hydrolysis after ingestion, thereby releasing the unconjugated parent mycotoxins $(7,11)$.

Beside the above mentioned ZEN14Glc and DON3Glc, there are several other plant conjugates identified and characterised in both artificial and natural samples. Lattanzio et al. (27) were the first to report T-2-glucoside (T-2-Glc) and HT-2-glucoside (HT-2-Glc) presence in naturally contaminated wheat and oats. T-2-Glc and HT-2-
Glc levels were about $12 \%$ of the parent mycotoxin. Glucoside forms of fusarenon-X (FUSX-Glc) and nivalenol (NIV-Glc) have been reported by Nakagawa et al. (28) in wheat artificially infected with Fusarium spp. They estimated that over $15 \%$ of fusarenon-X (FUSX) and nivalenol (NIV) are converted into glucosides. NIV-Glc occurrence in wheat was also reported by the EFSA (13). Nakagawa et al. (29) also found neosolaniol-glucoside (NEO-Glc) and diacetoxyscirpenol-glucoside (DAS-Glc), glucosides derived from type A trichotecenes, in corn powder mycotoxin reference material. The existence of oligoglycosylated forms of deoxynivalenol (DON) has been reported by Zachariasova et al. (30) in beer, malt, and bread

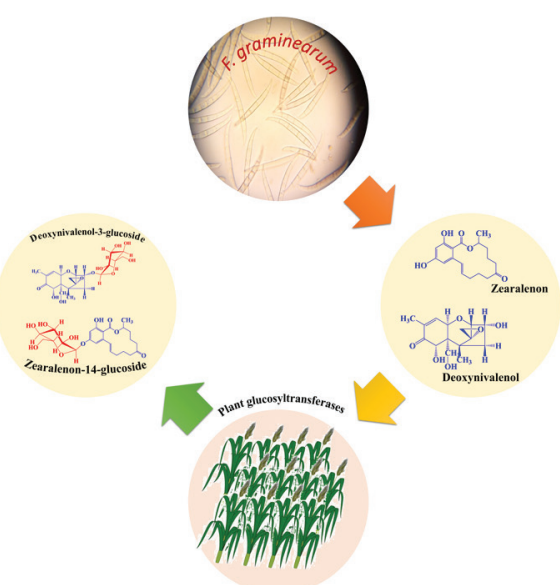

Figure 3 The "masking" of deoxynivalenol and zearalenone into deoxynivalenol-3-glucoside and zearalenon-14-glucoside 


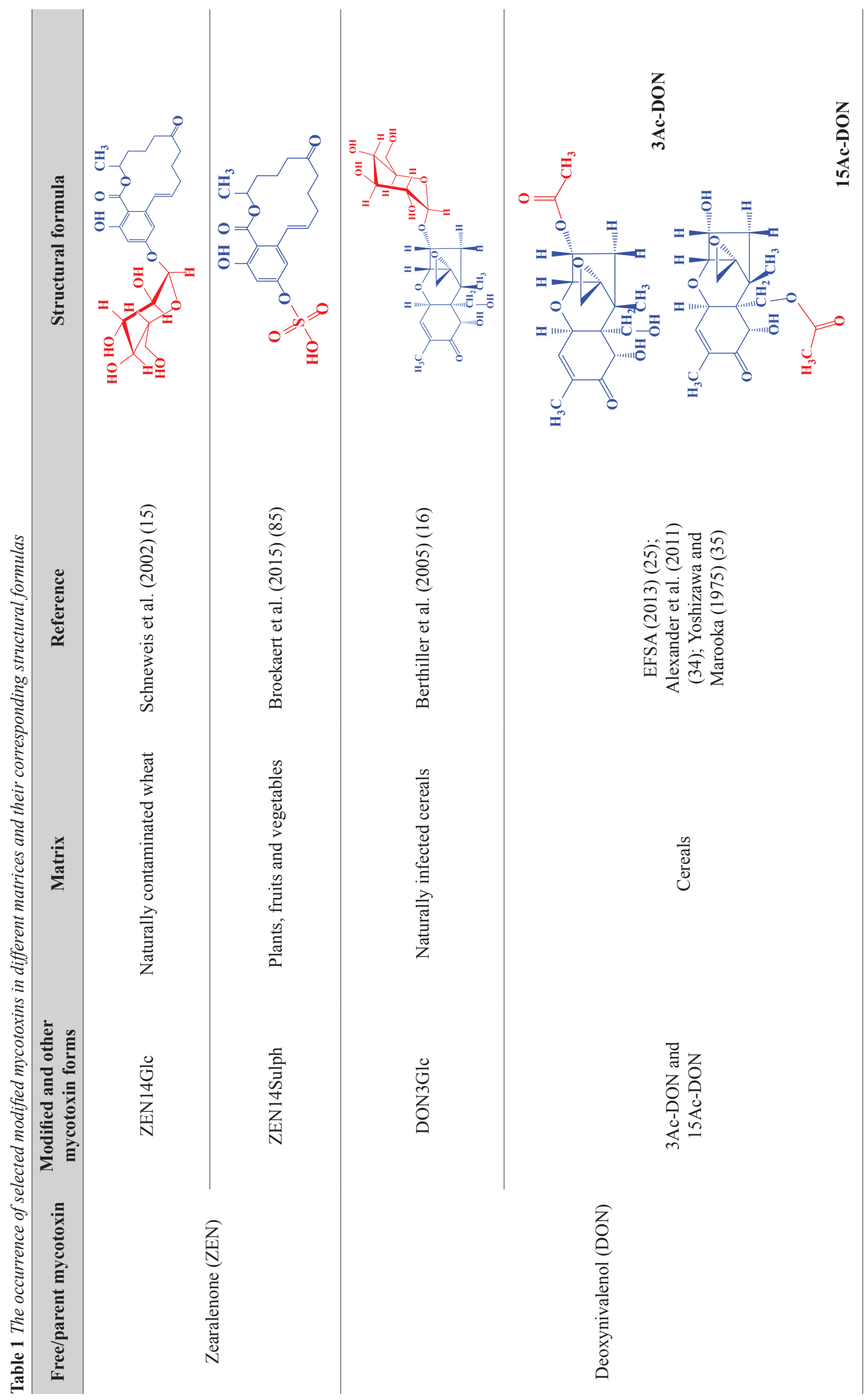




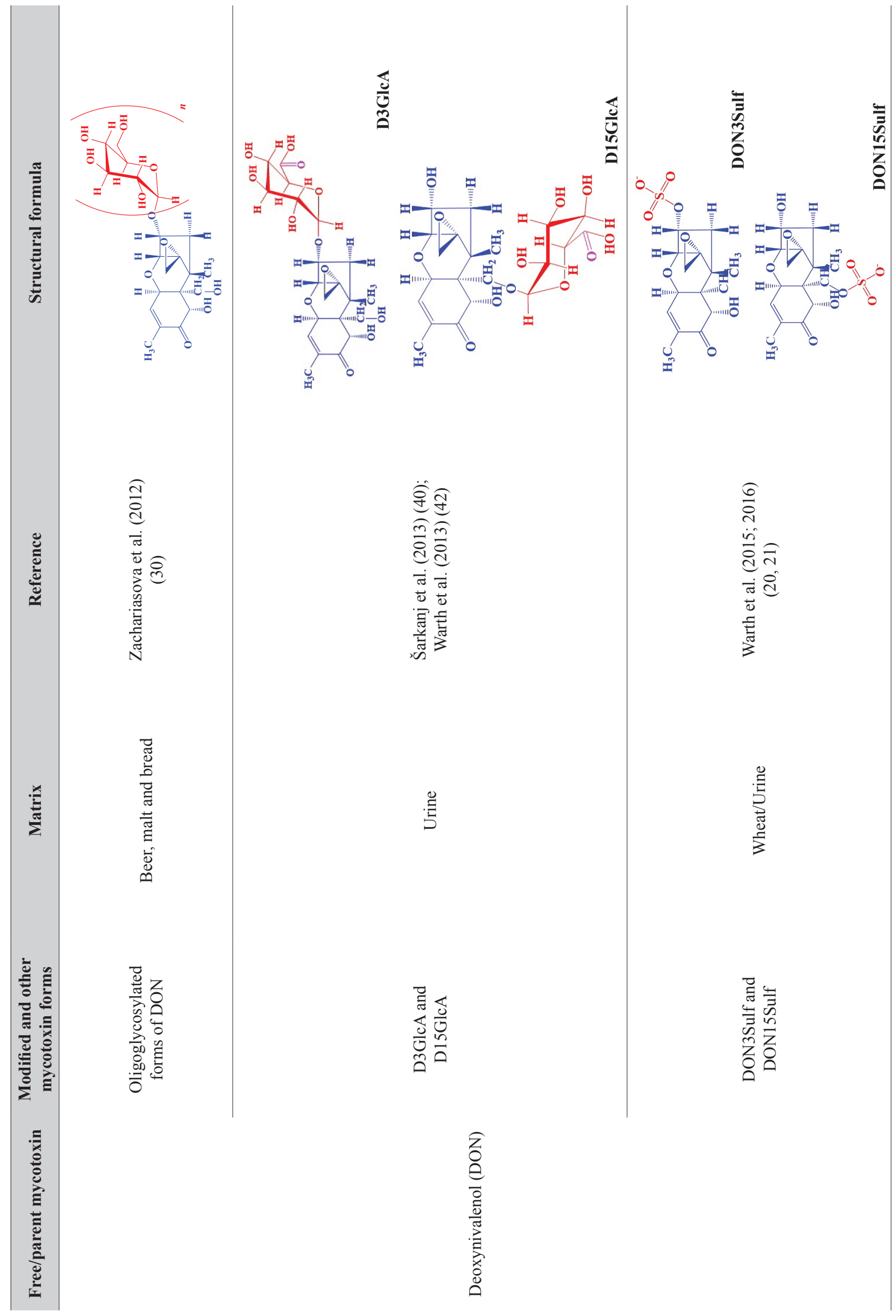




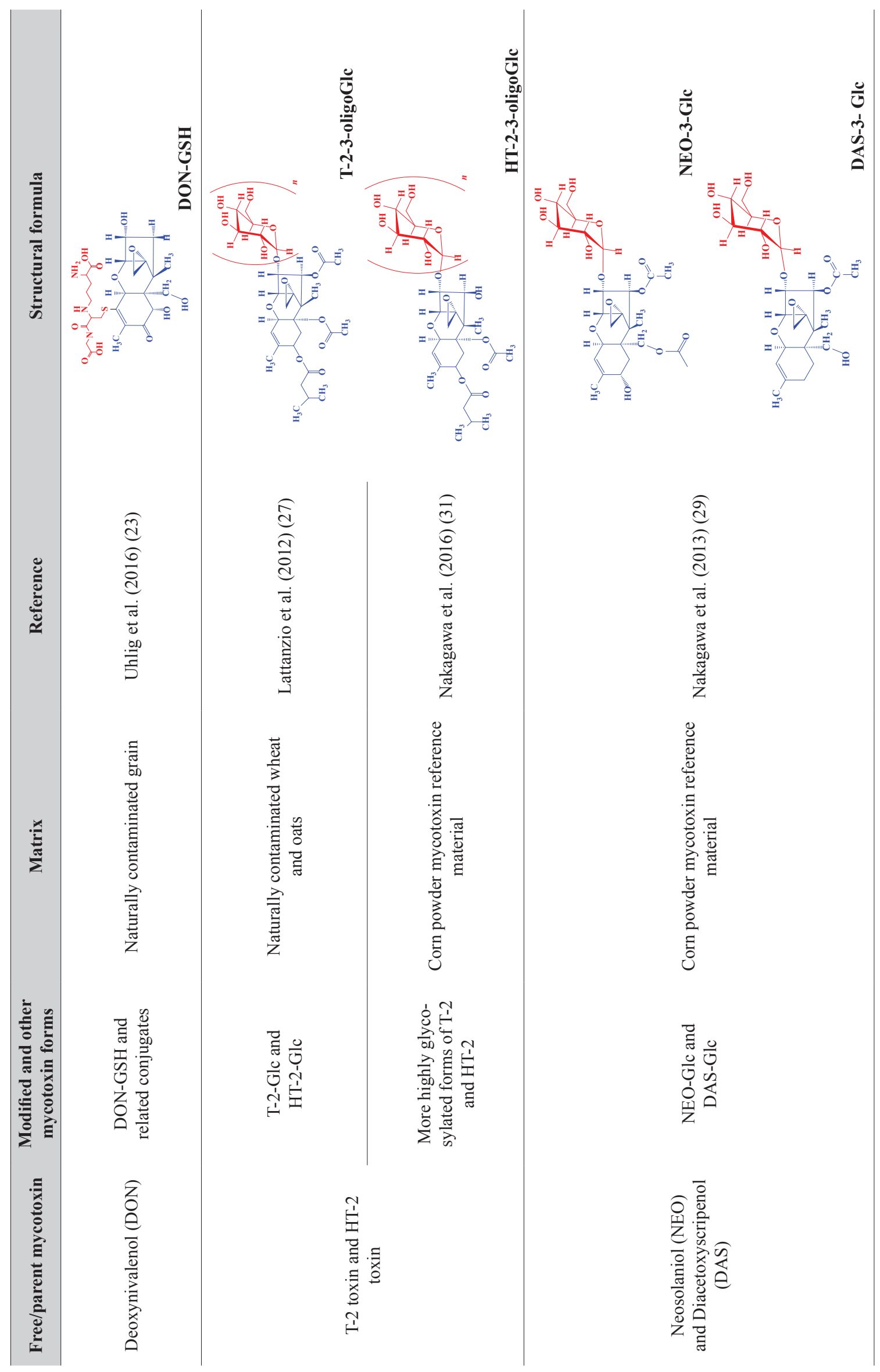




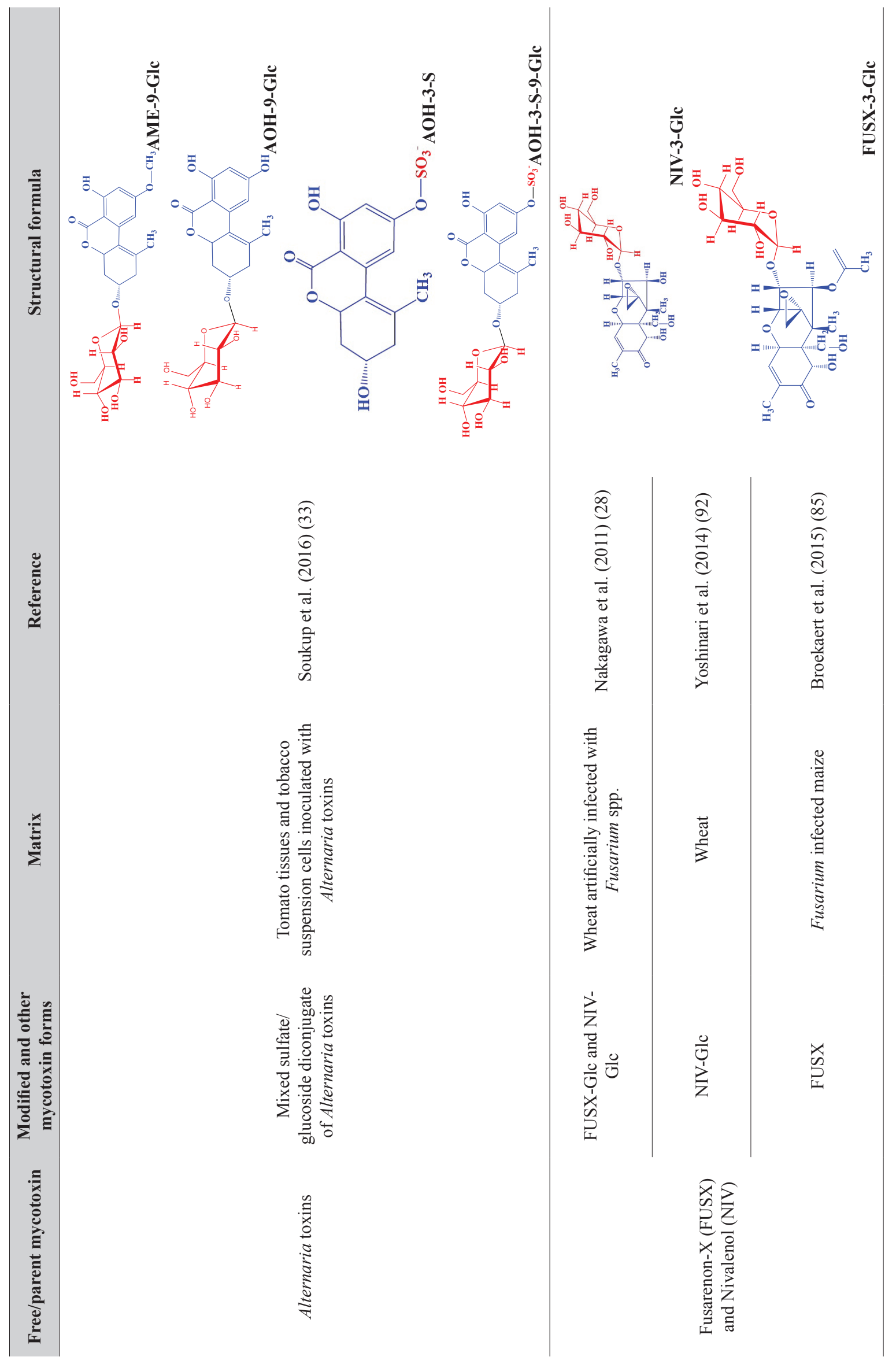




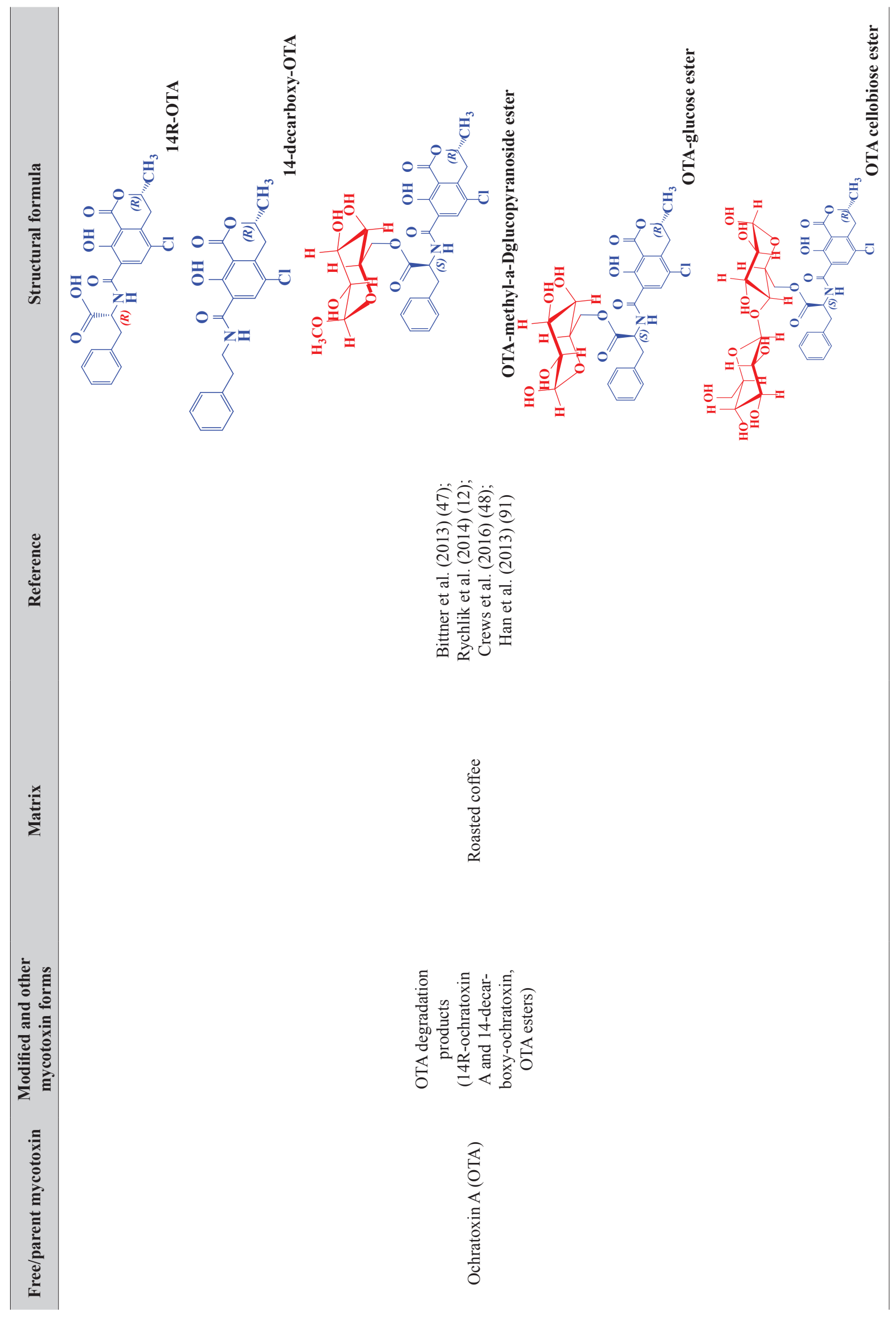




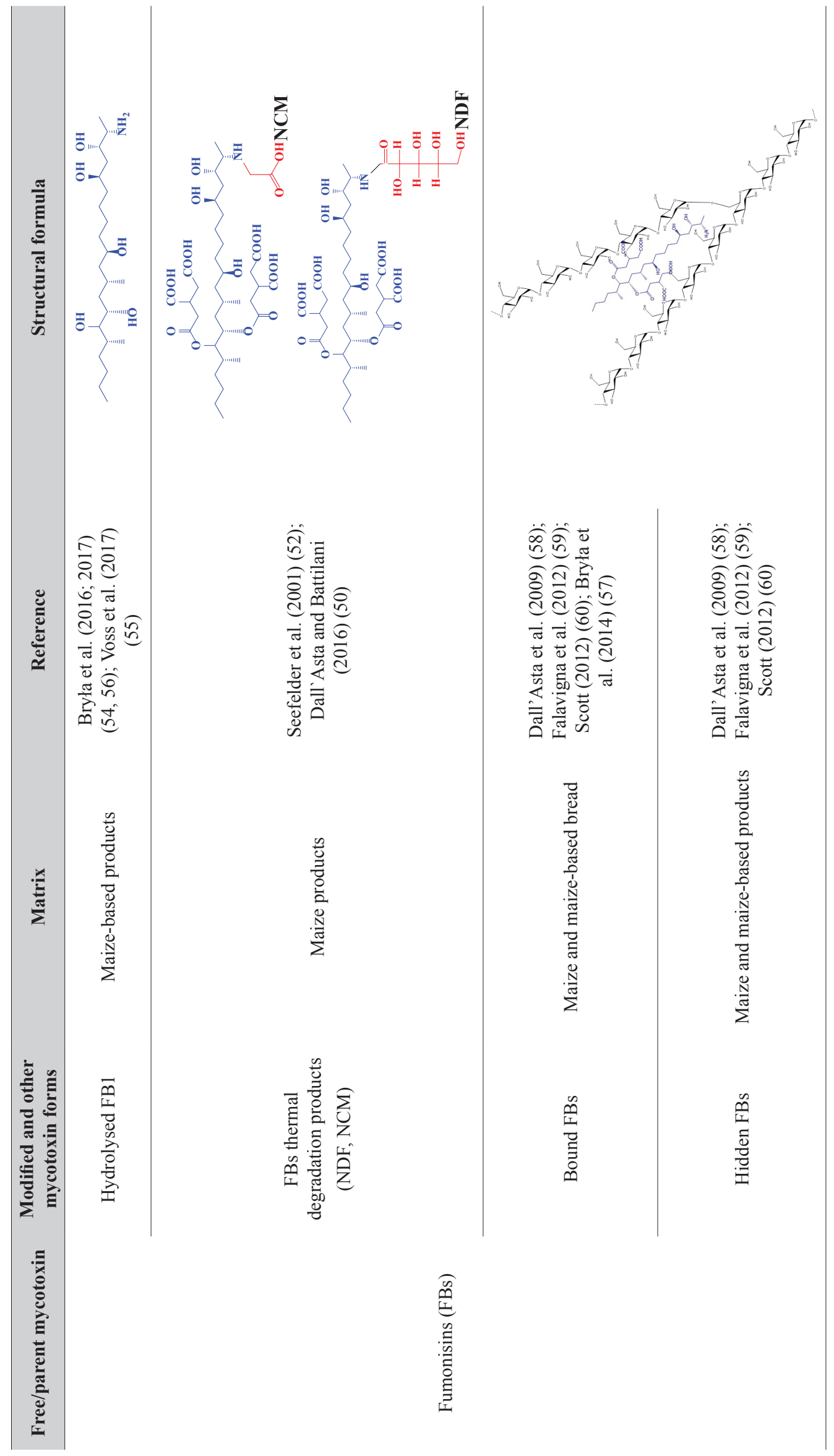


samples. More highly glycosylated forms of T-2 and HT-2 were also reported in corn by Nakagawa et al. (31).

Except for the typical glucolysated mycotoxin forms, other mycotoxin glycosides can occur, formed through conjugation by sulphatase (i.e. deoxynivalenol-suflates, DON3Sulf and DON15Sulf) (20) or glutathione S-transferase $(19,22)$. A glutathione DON adduct (DON$\mathrm{GSH})$, together with a range of related conjugates, has been investigated by Uhlig et al. (24) in naturally contaminated grain. The authors managed to identify glutathione (GSH), cysteinylglycine (CysGly), cysteine (Cys), $\gamma$-glutamylcysteine ( $\gamma$-GluCys), and $N$-acetylcysteine (NAC) coupled at the $13^{\text {th }}$ position on the epoxy group in the DON molecule, which was the first report of in vivo conjugation of trichotecenes via their epoxy group, generally considered as unreactive. Since DON-GSH is likely to be nontoxic and its formation irreversible, it was suggested that the identification of cereal genotypes that utilise the GSH-conjugation pathway may be useful in the future breeding strategies aiming to decrease DON accumulation in cereals (24). On the other hand, enhancing resistance to Fusarium spp. head blight (FHB) in wheat, often regarded as the best option to reduce fungal colonisation and mycotoxin contamination, showed to have an unexpected effect on masked mycotoxin content. According to Lemmens et al. (32), FHB-resistant wheat lines can metabolise DON to DON3Glc and decrease both DON and DON3Glc contamination. However, increased FHB resistance together with a decrease in DON content results in a conjugate increase in the relative fraction of the masked toxin compared to the parent. Such result is explained by the fact that increasing FHB resistance makes the reduction of DON content more efficient than the reduction of DON3Glc contamination.

In addition, other mycotoxin forms can occur, such as a mixed sulphate/glucoside diconjugate of a mycotoxin first reported by Soukup et al. (33) in 2016. The conjugates were found in tomato tissues and tobacco suspension cells inoculated with Alternaria toxins [alternariol (AOH), alternariomethyether (AME), tenauzonic acid (TEA), tentoxin (TTX) and others]. Regarding the fact that they can be formed by all mycotoxins and their phase I metabolites with two or more hydroxyl groups, the authors suggested that diconjugates should be taken into account in future modified mycotoxin analyses.

\section{Conjugation by fungi}

3-acetyl-deoxynivalenol (3Ac-DON) and 15-acetyldeoxynivalenol (15Ac-DON) are well known fungal conjugates. The production of these two biosynthetic precursors of DON was studied by Alexander et al. (34), who have elucidated the genetic basis for the difference between the 3- and 15Ac-DON chemo type. It was later found in a study with $F$. graminearum (11) that it is an esterase encoded by TRI8 which mediates the acetylation of trichotecene biosynthetic intermediates 3 and 15-diacetylDON at either the $\mathrm{C}-3$ or $\mathrm{C}-15$ position, and that its differential activity determines $3 \mathrm{Ac}-\mathrm{DON}$ or $15 \mathrm{Ac}-\mathrm{DON}$ formation. $3 \mathrm{Ac}-\mathrm{DON}$ and $15 \mathrm{Ac}-\mathrm{DON}$ have generally been reported to occur together with DON (25). According to the EFSA opinion of 2013 (25), the average contribution of $3 \mathrm{Ac}-\mathrm{DON}$ to the sum of DON and its derivatives was $<2 \%$ at the lower-bound estimate and $13-20 \%$ at the upper bound estimate, and of 15Ac-DON 10-15\% at both lower and upper bound estimates. As early as 1975, Yoshitzawa and Morooka (35) made one of the first attempts to elucidate acetyl transformation of DON by trichothecene-producing strains of Fusarium nivale, F. roseum, and F. solani.

FUSX is another fungal conjugate that is a precursor in the biosynthesis of NIV. The presence of FUSX has already been proven in Fusarium infected maize, even though the concentrations and the incidence were small (11).

Fungi also have the ability to metabolise mycotoxins produced by mycotoxigenic fungi. The case in point is zearalenone (ZEN) and the formation of zearalenone-14sulphate (ZEN14Sulph) in the saprobic Rhizopus fungus, frequently found on plants, fruits, and vegetables (11).

\section{Conjugation by mammals}

Conjugates formed by mammalian mycotoxin metabolism in the liver and excretion via urine are unlikely to play any important role in food (7) but are worth mentioning to get a comprehensive overview of the topic. Common mycotoxin conjugates produced by mammals are $\operatorname{DON}(36,37)$ and ZEN (37-39) glucoronides and sulphates. Mammalian conjugates in urine can serve as biomarkers of exposure to certain mycotoxins. This is particularly true since a dose-response relationship has been established by Šarkanj et al. (40) in pregnant women from Croatia. ADON glucuronide was first suggested by Meky et al. in 2003 (41) and DON-3-glucoronide (D3GlcA) and DON-15glucoronide (D15GlcA) first identified and characterised in naturally contaminated urine samples and human and animal liver microsomes a decade later $(42,43)$. The third glucuronide, DON-7-glucoronide (D7GlcA), was suggested and confirmed in 2013 (40). A recent report by De Boevre et al. (44) added to the list another DON glucuronide, with a possible hydroxylation point at $\mathrm{C}-8$ position.

Beside conjugation, mammalian metabolism can create a cleavage, such as the one of phenylalanine moiety in ochratoxin A (OTA), and produce ochratoxin alpha (OT $\alpha$ ) (Figure 4). To eliminate OTA and OT $\alpha$, animals resort to glucuronidation, and the new glucuronides can occur on several positions: OTA-acyl-GlcA, OTA-phenol-GlcA, and OTA-amino-GlcA. OT $\alpha$ is also glucuronidated and mainly excreted via urine as OT $\alpha$-acyl-GlcA and OT $\alpha$-phenol-GlcA (Figure 4). The conjugated forms of OTA and OT $\alpha$ have been confirmed only indirectly with and without enzymatic hydrolysis of biological fluids of subjects exposed to OTA (45). 


\section{Food processing effects}

The effects of food processing on the stability of free mycotoxins have been well researched, but on modified or unregulated mycotoxins far less so. Still, we do know that food processing can significantly contribute to the formation and the final concentrations of modified mycotoxins in certain food products $(11,46)$.

One such process is coffee roasting, which causes the formation of several degradation products of OTA (Figure 4), such as 14R-ochratoxin A and 14-decarboxy-ochratoxin $(12,47,48)$. According to Bittner et al. (47), further thermal reaction leads to the binding of OTA to coffee polysaccharides via esterification and production of OTA esters such as OTA-glucose ester, OTA-methyl- $\alpha$-D-glucopyranoside ester, and OTA-cellobiose ester (Figure 4).

Effects of extrusion on mycotoxins depend on time and temperature of the process, as well as on other factors. In the case of fumonisins (FBs) (Figure 5), the presence of additives, reducing sugars, and sodium chloride is crucial (46). Studies indicate that the greatest reduction of FBs occurs in the presence of glucose at $160{ }^{\circ} \mathrm{C}$ or more $(13$, 46, 49). In the Maillard-type reaction with reducing sugars, this loss in FB content likely reflects on the formation of degradation products $N$-carboxymethyl fumonisin B1 (NCM-FB1) and $N$-deoxyfructosyl fumonisin B1 (NDFFB1) $(50,51)$. These fumonisin derivatives have been reported in maize products by Seefelder et al. (52), and their toxicity investigated by Hartl and $\operatorname{Humpf}(53)$. In addition, the hydrolysed form of fumonisin B1 (HFB1) created by the cleavage of both carballylic moieties (Figure 5) is commonly obtained upon alkali treatment $(13,50)$, for example in the production of traditional tortillas in South America (46). Due to similar chemical properties of FBs and HFBs, the reaction scheme proposed for the modification of FB1 to NCM-FB1 and NDF-FB1 can also apply for the modification of FBs and HFBs (Figure 5). The occurrence of HFBs was recently investigated by Bryła et al. (54) in maize-based products, who concluded that the masked to free fumonisin concentration ratio in thermally processed food such as corn flakes and various snacks was higher than in unprocessed products such as flour or raw popcorn grains due to food processing. Voss et al. (55) have also confirmed that extrusion and nixtamalisation can reduce FB toxicity through hydrolysation. In 2017, Bryła et al. (56) investigated the effect of $\mathrm{pH}$ and baking temperature on the stability of FBs in a maize product and confirmed that FBs are decomposed to HFBs and partly hydrolysed FBs. Thermal processing of up to $250{ }^{\circ} \mathrm{C}$, did not, however, degrade the FBs. The authors also detected that only $20 \%$ of FBs were bound and that lower dough $\mathrm{pH}$ increased the bound FB content. Earlier, the same group of authors found FBs physically entrapped into the structure of macromolecular components such as starch during bread making (57). These FBs were entrapped in a gluten-free bread up to $80 \%$ of the parent form. They have also reported a smaller decrease in the content of hidden FBs compared to the free molecules, which was explained by a matrix stabilisation effect (57). In addition, these forms of FBs formed through an associative interaction between the toxin and matrix

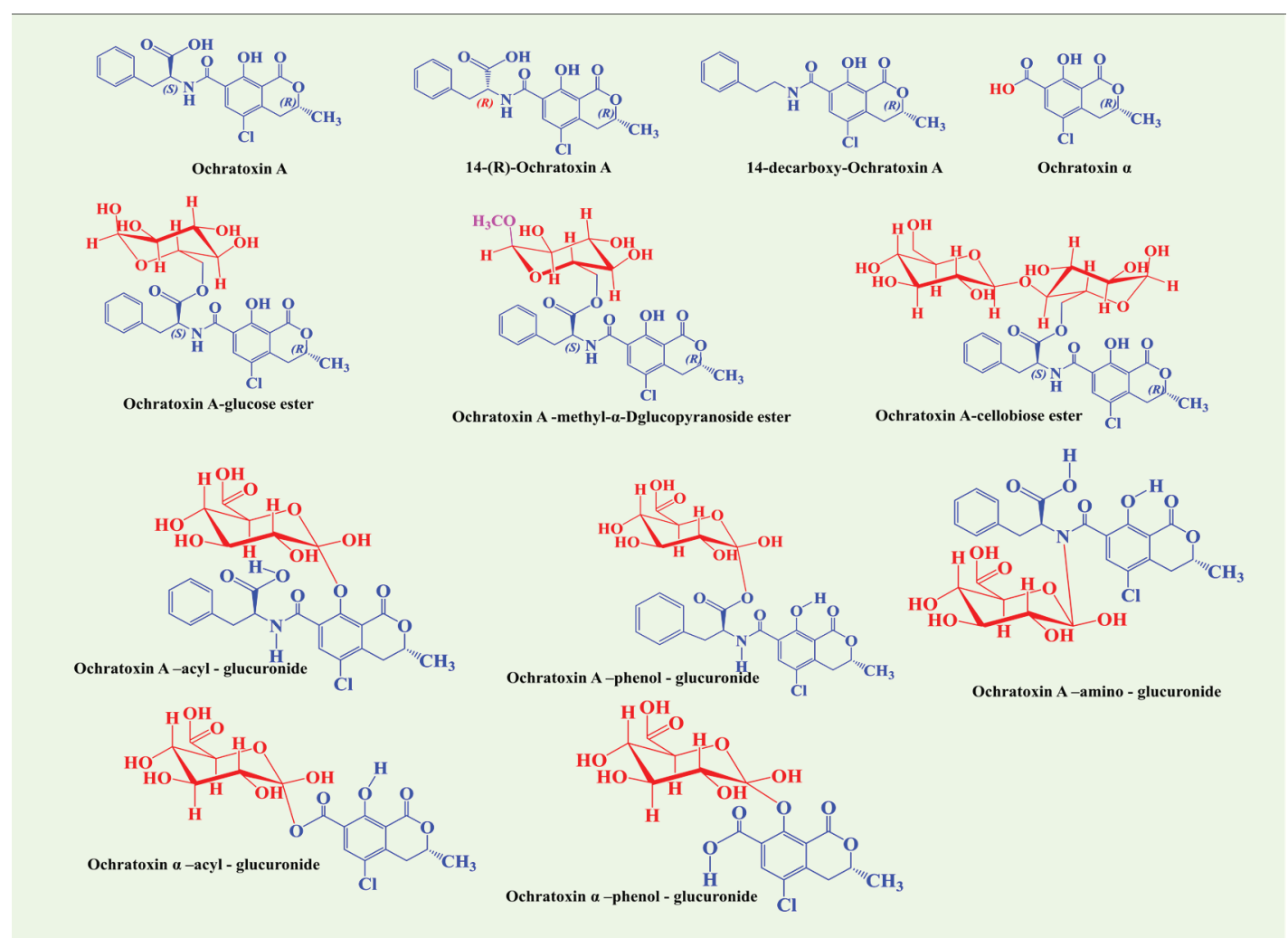

Figure 4 The structures of ochratoxin A, its metabolites, and processing by-products $(45,91)$ 
macroconstituents are in the literature often called "hidden", while the above mentioned FBs, covalently linked to any matrix constituents, are referred to as "bound" (58-60). Even though the entrapping mechanism is still to be clarified from the physicochemical point of view, the existing data indicate that biopolymers such as amylose and amylopectin can form inclusion complexes with FBs. These forms can easily degrade under in vitro digestion conditions and are therefore toxicologically relevant (50).

The fate of DON and DON3Glc during bread making was studied by several other authors (30,61-63). Vidal et al. (61) reported that baking reduced the concentration of DON but increased that of DON3Glc. They attributed this rise to glycosidation of DON in the initial stages of baking, before enzyme inactivation. This hypothesis is supported by the fact that DON3Glc also increases during fermentation, as previously suggested by Zachariasova et al. (30). The most recent, 2017 study by Generotti et al. (17) investigated the effects of baking on the final trichotecene (DON, DON3Glc, and Fusarium metabolite culmorin) content by modifying technological parameters and recipe ingredients. The results suggest that $\mathrm{pH}$ and baking time have an important role in minimising mycotoxins in the final product, while changes in the recipe can change mycotoxin extractability by affecting biscuit microstructure. Higher $\mathrm{pH}$ during wholegrain biscuit production reduced DON concentrations. Baking time effectively reduced DON and DON3Glc content in the final product (up to $80 \%$ ). Culmorin concentrations positively correlated with DON.

Beer production, in turn, raises great concern about possible formation and transfer of Fusarium mycotoxins from raw materials to final beer products $(13,46)$. A significant increase in the level of DON3Glc was observed during malting and brewing $(64,65)$. An increase was also observed in the levels of acetylated DON forms (AC-DONs) across the beer production chain (64). Their levels in barley were about $40 \%$ of free DON, while in beer they were comparable or higher $(64,66)$. Even though there are several theories explaining the increase in DON3Glc, there are two phenomena that should be considered. The first includes de novo growth of Fusarium spp. during malting, accompanied by the production of additional mycotoxins and their transformation products. The second phenomenon relates to the degradation of cell walls, membrane-bound proteins, and starch depots by enzymes produced during mashing of malt grits, which leads to releasing DON3Glc from insoluble forms $(18,65)$.

Recently, Karlovsky et al. (67) gave an overview of how food processing and detoxification treatments relate to mycotoxin contamination. In some cases, food processing reduces mycotoxin content, such as cleaning, milling, brewing, fermentation, cooking, baking, roasting, alkaline cooking, nixtamalisation, and extrusion. However, food processing can seldom completely eliminate mycotoxins from a food product. The authors pointed out that the disappearance of parent mycotoxin does not necessarily mean detoxification because of its conversion into a "masked" form that escapes detection and has unknown toxic potential. They also allowed the possibility of cocontamination with other mycotoxin-producing fungi (63).

\section{OCCURRENCE}

The information on mycotoxin occurrence in food and feed is crucial for the assessment of consumer exposure and for setting maximum regulatory levels for certain products. It is general perception that mycotoxin levels have been underestimated exactly because of the modified mycotoxins (48). Over the past few years, however, the occurrence of the modified forms has been extensively researched, DON3Glc and ZEN14Glc in particular. Malachová et al. (68) monitored the occurrence of several mycotoxins in 116 cereal-based products from the Czech market. DON was found in $75 \%$ of samples with its levels varying between 13 and $594 \mu \mathrm{g} \mathrm{kg}^{-1}$, while the prevalence of DON3Glc was even higher $(80 \%)$ and its levels ranged between 5 and $72 \mu \mathrm{g} \mathrm{kg}^{-1}$. The latter was found in a single whole-grain slice product (68).

The occurrence of DON, DON3Glc, and 3Ac-DON in beer was investigated by Varga et al. (66). 3Ac-DON was not found in any of 384 beer samples from 38 countries, but DON3Glc and DON were found in 93 and $77 \%$ of the samples, averaging $6.9 \mu \mathrm{g} \mathrm{L}^{-1}$ and $8.4 \mu \mathrm{gL}^{-1}$, respectively.

De Boevre et al. (69) analysed 30 food and feed samples (maize, wheat, oats, cornflakes, and bread) from Belgium for ZEN, ZEN14Glc, DON, DON3Glc, and AC-DON. DON was the most common contaminant in both cereals and cereal-derived food. 3Ac-DON and 15Ac-DON were found in $87 \%$ and $73 \%$ of the samples, respectively. $66 \%$ of the analysed samples were contaminated with DON3Glc, with the highest levels in maize samples (max. $1003 \mu \mathrm{g} \mathrm{kg}^{-1}$ ). Regarding the DON equivalents, of the total DON content, $62 \%$ were metabolites, whereof $17 \%$ were the glycosylated form DON3Glc. The occurrence of ZEN was $80 \%$, while its glycosylated and sulphated forms were detected in $40 \%$ of the samples (69).

Cereal-based products (fibre-enriched bread, branenriched bread, breakfast cereals, popcorn, and oatmeal) from Belgium were also analysed by De Boevre et al. (44) for the occurrence of DON, DON3Glc, AC-DONs, T-2, HT-2, and ZEN and its conjugates. All 174 samples were co-contaminated with three to eight mycotoxins, including one to three modified forms. DON was the major contaminant of wheat-based matrices. DON3Glc was found in half of the fibre-enriched bread samples and breakfast cereal samples and in 77 and $92 \%$ of popcorn and oatmeal samples, respectively. The highest prevalence of AC-DONs was recorded in popcorn, followed by oatmeal samples, and $3 \mathrm{Ac}-\mathrm{DON}$ was more frequent than 15Ac-DON. ZEN prevalence was the highest in oatmeal samples (62\%), 


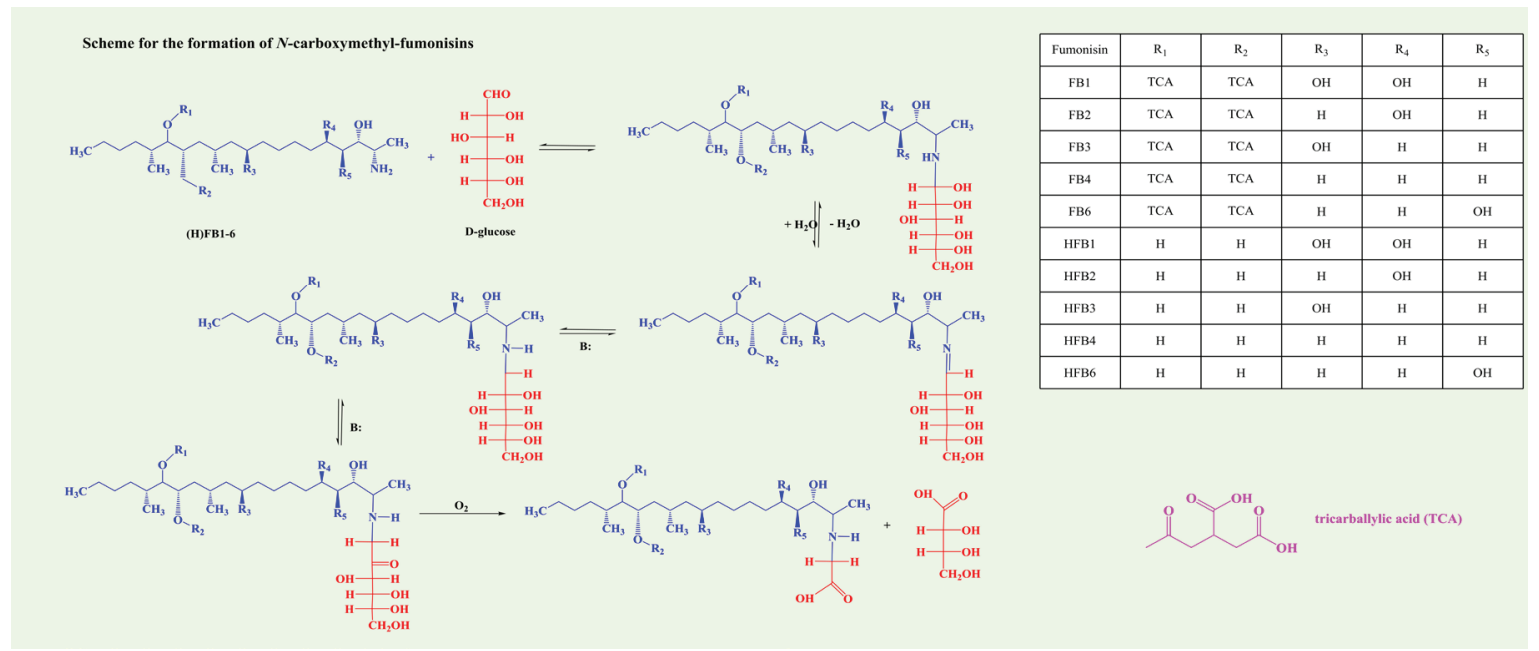

Figure 5 Formation of N-carboxymethyl-fumonisins

The structures of fumonisin B1-6 (FB1-6); hydrolysed fumonisin B1-6 (HFB1-6); N-carboxymethyl fumonisin B1-6 (NCM-FB1-6); $\mathrm{N}-$ deoxyfructosyl fumonisin B1-6 (NDF-FB1-6); N-carboxymethyl hydrolysed fumonisin B1-6 (NCM-HFB1-6); and N-deoxyfructosyl hydrolyzed fumonisin B1-6 (NDF-HFB1-6)

while that of ZEN conjugates was the highest in breakfast cereal samples (roughly $30 \%$ ).

An extensive global research of animal feed contamination by mycotoxins by Kovalsky et al. (1), that included 1113 samples (of finished feed, maize, and maize silage) collected between 2012 and 2015 from 44 countries and analysed for 57 mycotoxins and metabolites, showed that the regulated toxins, DON, ZEN, and to a certain extent FBs had the highest levels. ZEN contaminated $88 \%$ of the investigated matrices and DON $79 \%$. The prevalence of the related masked forms ZEN14Sulph and DON3Glc was also high: $47 \%$ and $70 \%$, respectively. The authors also established a positive correlation between DON and ZEN and their masked forms. In addition, the authors observed distinct trends of mycotoxin occurrence within a region over the years, suggesting the importance of cultivars and local weather (1).

Even though the data on the occurrence of modified mycotoxins are coming to light all over the world, this cannot be said for Croatia. There are only a few reports of masked mycotoxin levels in Croatian cereals: $47.8 \mu \mathrm{g} \mathrm{kg}^{-1}$ for DON3Glc and $176.6 \mu \mathrm{g} \mathrm{kg}^{-1}$ for DON3Glc in wheat (40), and $546 \mu \mathrm{g} \mathrm{kg}^{-1}$ for DON3Glc and $788 \mu \mathrm{g} \mathrm{kg}^{-1}$ for DON3Glc in maize (70).

\section{ANALYTICAL ASPECTS}

Obviously, there are no accurate data on the occurrence of free and modified mycotoxins without reliable analytical methods. There are many chromatographic methods, mainly based on liquid chromatography (LC), and immunochemical methods, such as enzyme-linked immunosorbent assays (ELISA), that provide reliable measurement of free mycotoxins. However, the latter are still not selective enough for modified mycotoxins, as they sometimes respond to more than one compound and yield a single, fake positive, or overestimated result $(7,12,13)$. This "cross-reactivity" effect was evidenced for DON, ACDONs, and DON3Glc. The latter two can contribute to DON content overestimation in some matrices $(7,71)$. Yet, cross-reactivity can be useful in determining modified mycotoxins. For instance, commercially available immunoaffinity columns (IACs) for DON analysis are known to cross-react with its analogues DON3Glc, 15AcDON, and 3Ac-DON to a variable extent, which can be a valuable tool for evaluating total DON content in samples (72).

In general, mycotoxin analysis is a complex process which requires proper sampling (strategies), sample preparation, detection, and quantification by means of suitable analytical instruments. Sample preparation implies extraction of the toxin from the matrix with suitable solvent, clean-up of the extract in order to eliminate interferences from the matrix, and sample concentration if necessary. The analysis of modified mycotoxins is even more complicated and usually involves one of the two approaches: direct or indirect $(7,12,13)$. The direct approach employs the conventional, standardised methods developed for free mycotoxin determination but adjusted and optimised to suit the properties (polarity, extraction behaviour, detection characteristics) of targeted modified mycotoxins. The major drawback of the direct approach is the lack of analytical standards necessary for the analysis of all masked or modified forms of mycotoxins. The indirect approach, in turn, is usually based on chemical and/or enzyme treatment to transform modified forms into their parent mycotoxin, which can then be determined with routine analysis. The downside is that the information it provides does not distinguish between free and modified mycotoxins.

This is why direct LC-MS methods have become methods of choice when it comes to modified mycotoxin determination (12). For over a decade, LC-MS/MS has been the golden standard for routine food safety control, as it 
ensures analytical parameters that meet the quality criteria required by law. Mycotoxin analysis now as a rule uses QqQ mass spectrometry analyser and multiple reaction monitoring (MRM). Being selective, mass spectrometry no longer requires clean-up steps and is particularly useful for simultaneous determination of multiple mycotoxins and their metabolites. The first multi-mycotoxin method was developed by Sulyok et al. (73) in 2006 for the quantification of 39 free and modified mycotoxins in wheat and maize, including AC-DONs, DON3Glc, ZEN14Glc, ZEN14Sulph, and hydrolysed FB1. More recently, Jackson et al. (74) developed a method for the quantification of free and modified mycotoxins in feed samples, and De Boevre et al. (69) for simultaneous determination of mycotoxins in cereals and cereal-derived food. In 2014, Malachová et al. (75) expanded Sulyok's method (73) to the determination of 295 fungal and bacterial metabolites, including free and modified mycotoxin forms.

Yet, these QqQ methods have their limitations. Firstly, the number of analytes that can be analysed in a single run is restricted by the MS/MS quality. Secondly, only targeted compounds can be detected, and quantification requires the use of analytical standards, which limits determination of most modified mycotoxins (2). Thirdly, accurate mycotoxin quantification in different matrices requires matrix-assisted calibration or appropriate internal standard, and these standards and (certified) reference materials are still not widely available. There are several producers who now provide modified DON, T-2, HT-2, and Alternaria mycotoxins (Romer labs ${ }^{\circledR}$, Toronto Research Chemicals, Sigma Aldrich ${ }^{\circledR}$ and others) to overcome this limitation.

Recently, full-scan techniques have been studied as a way to complement the QqQ methods. LC coupled to high resolution mass spectrometers (HRMS) has the advantage over QqQ, as it enables target analysis, identification of new non-targeted compounds, and retrospective data analysis $(2,13)$. While it may be less sensitive than QqQ, LC-HRMS orbitrap is regarded as a powerful tool for multiclass, multi-analyte analysis in food safety (76). It has been used in a number of studies to scan for and measure modified DON, $(19,77)$ modified type A trichotecenes (29), OTA polysaccharide esters (47), or glycosyl derivatives of T-2 and HT-2 (27).

However, HRMS still needs to resolve issues such as isobar co-elution and unknown molecule identification to become a fully effective food safety control tool. These issues have been addressed by the introduction of ion mobility spectrometry (IMS), which can provide a better insight into the formation and characterisation of novel modified mycotoxins, but requires further testing (2). Another issue of HRMS are the levels of detection, which are much higher than with QqQ. In practical terms, fewer naturally contaminated samples can be quantified by HRMS. Furthermore, HRMS is associated with a huge number of artefacts and nonspecific peaks in real samples, so the use of C-13-labelled standards or sample pairs is necessary for positive identification of new components (19).

In terms of mycotoxin determination in the future, multi-mycotoxin LC-MS/MS and LC-HRMS methods will continue to play an important role in screening, confirmation, and quantification of hundreds of fungal metabolites in food and feed samples and will be complemented by metabolomics in order to reveal the fundamental biological processes behind mycotoxin production and its reduction (78).

\section{TOXICOLOGICAL RELEVANCE}

Knowledge about the toxicological relevance of modified mycotoxins is still modest (79-81). Most of the concerns address the potential health effects of conjugated and matrix-associated mycotoxins, mainly due to indirect toxicity via hydrolysis to their free forms $(11,12,79,80)$.

\section{In vitro studies}

By mimicking natural conditions during digestion, in vitro studies examine the fate of modified mycotoxins in contact with stomach juices and interaction with human colonic microbiota. So far, these studies have mostly focused on the derivatives of ZEN and DON $(11,12)$. A 2013 study by Dall'Erta et al. (79) has been the first to demonstrate that DON and ZEN conjugates are effectively cleaved by the human colonic microbiota. In the process they release their aglycones and generate unidentified catabolites. The authors showed nearly the full recovery of DON3Glc, ZEN14Glc, and ZEN14Sulph by enzymatic treatments $(99.5 \%, 97.3 \%$, and $98.6 \%$, respectively). The effects of human colonic microbiota were analysed in the first $30 \mathrm{~min}$ and at $24 \mathrm{~h}$ of fermentation. The ZEN derivatives were completely cleaved after $30 \mathrm{~min}$, while ZEN was only partially recovered in the faecal slurry (39\% after $30 \mathrm{~min}$ and $40 \%$ after $24 \mathrm{~h}$ ), which implied the possibility of further ZEN degradation into unknown compounds. DON3Glc was almost completely degraded after $24 \mathrm{~h}(11,79)$.

In 2016, Cirlini et al. (82) reported that ZEN14Glc and its positional isomer ZEN16Glc crossed the cell barrier and were absorbed by Caco- 2 cells in a time- and concentrationdependent manner. The conjugates were cleaved to release the parent molecule, and ZEN14Glc was more prone to deglycosylation than ZEN16Glc. The authors also showed that human cytosolic b-glucosidase cleaved ZEN14Glc but not ZEN16Glc, and that ZEN14Glc and ZEN16Glc were hydrolysed inside the cell. This implies that ZEN generated in situ can be taken up by intestinal cells and metabolised into phase I and phase II metabolites, which can contribute to the overall oestrogenic load.

Pierron et al. (83) also used Caco-2 cells to assess the ability of DON3Glc to elicit a ribotoxic stress and induce intestinal toxicity. DON3Glc did not bind to the main targets of DON toxicity and therefore did not activate JNK and 
P38 MAPK pathways in Caco-2 cells or change their viability and barrier function. The authors concluded that glucosylation of DON suppressed its ability to bind to the ribosome and decreased its intestinal toxicity.

One in vitro digestion assay proved the stability of $\mathrm{FB}$ covalent conjugates (bound fumonisins) (59), while another (84) showed that FBs forming complexes with matrix macroconstituents (hidden FBs) released their free forms and became available for intestinal absorption. The static model used by Dall'Erta et al. (79) was also used to analyse modified FBs. These studies suggest that even if FB levels in products do not exceed the legal limit, digestion can increase their bioavailability through hidden FBs. This brings us back to the need to include masked mycotoxins in any serious risk assessment.

Considering that the intrinsic cytotoxicity of modified DON3Glc, 3Ac-DON, and 15Ac-DON (AC-DONs) has not been investigated as extensively as of their parent mycotoxins, Broekaert et al. (85) compared their in vitro cytotoxicity towards differentiated and proliferative porcine intestinal epithelial line derived from the jejunum (IPEC-J2). The cytotoxicity of DON and its modified forms after a 72-hour exposure was as follows: DON3Glc $<<3 \mathrm{Ac}$ $\mathrm{DON}<\mathrm{DON} \approx 15 \mathrm{Ac}-\mathrm{DON}$. The authors, however, emphasized that cytotoxicity to IECs was only one toxicological endpoint, while other, such as the effects on the immune system, could have significantly more or less sensitive dose-response curves.

Beside in vitro studies, Dellafiora et al. (86) carried out an in silico study to gain an insight into the systemic fate of ZEN14Glc. They monitored the hydrolysis and the transformation of the masked mycotoxin in bovine blood and blood components. All matrices showed hydrolysis, and the whole blood showed ZEN isomers. Further assessment of (bio)transformation in the blood stream is needed to better understand the in vivo action of $\mathrm{ZEN}$ and its modified forms.

In vivo studies

The first reported study on modified mycotoxins in vivo comes from 1990, when Gereis et al. (87) noted a decomposition of ZEN14Glc in pigs and detected ZEN and its metabolites in urine and faeces. Although they evidenced the complete hydrolysis of ZEN14Glc, they found no associated clinical signs of oestrogenic activity. Two decades later, Veršilovskis et al. (88) reported unstable ZEN14Glc in rat stomach (35\% and $46 \%$ were recovered), which rapidly hydrolysed to free ZEN. In the intestine only small amounts of ZEN14Glc were observed $(0.5 \%$ in the small intestine, $2.5 \%$ in the colon). Both studies evidence that ZEN14Glc is rapidly hydrolysed in vivo and that its contribution to overall mycotoxin toxicity is highly probable. However, to fully understand toxicokinetics and species differences further research is needed $(80,81)$.
Veršilovskis et al. (88) also reported $37 \%$ and $51 \%$ recovery of DON3Glc in the stomach, whereas the release of DON was only $2 \%$. In the small and large intestine no free DON and small traces of DON3Glc were found. In another study by Nagl et al. (89) only a very small percentage of DON3Glc was found in urine after administration, while the majority was found in faeces, indicating that faecal excretion is the major route of DON3Glc elimination in rats. The authors have suggested that DON3Glc in food and feed is less toxic than DON but have also allowed that its bioavailability and metabolism are species-dependent due to differences in the anatomy and gut microbiota. Two years later the same group of authors (90) studied the possibility of DON3Glc cleavage during ingestion in pigs. After the oral dosing of DON3Glc, urinary DON was the main excretion product after $24 \mathrm{~h}$, while only trace amounts of the metabolite were found in faeces. These findings indicate that DON3Glc is almost completely hydrolysed in the gastro-intestinal tract of pigs. Compared to its parent form, DON3Glc seems to be less bioavailable and therefore less relevant toxicologically. However, the authors emphasised the possibility of DON3Glc having a biological activity of its own, which deserved more attention.

\section{CONCLUDING REMARKS}

The term masked mycotoxin was initially used to highlight difficulties in the detection of certain compounds by routine analysis. To avoid misunderstanding and introduce uniform interpretation, especially in legislation, the term has been limited to cover only biologically modified mycotoxins conjugated by plants.

Mass spectrometers brought the possibility to analyse several mycotoxins at once and simplified the discovery of novel compounds. Consequently, it has become evident that modified mycotoxins co-exist with their native compounds in contaminated agricultural commodities, sometimes in the same or even higher level. This has raised the question of their toxicological relevance and adverse health effects. Toxicological studies have confirmed that certain modified mycotoxins are hydrolysed into their free forms after the ingestion. However, further research is needed to fully clarify their fate upon ingestion. Their physiological and toxicological role should also be assessed, because some of the toxins may not act as their parent compound. The outcome of these toxicological researches will hopefully drive the legislators to expand regulations to encompass both free and modified mycotoxins.

\section{REFERENCES}

1. Kovalsky P, Kos G, Nährer K, Schwab C, Jenkins T, Schatzmayr G, Sulyok M, Krska R. Co-occurrence of regulated, masked and emerging mycotoxins and secondary 
metabolites in finished feed and maize - an extensive survey. Toxins 2016;8:363. doi: 10.3390/toxins8120363

2. Righetti L, Paglia G, Galaverna G, Dall'Asta C. Recent advances and future challenges in modified mycotoxin analysis: Why HRMS has become a key instrument in food contaminant research. Toxins 2016;8:361. doi: 10.3390/ toxins 8120361

3. Berthiller F, Maragos CC, Dall'Asta C. Introduction to masked mycotoxins. In: Dall'Asta C, Berthiller F, editors. Masked mycotoxins in food - formation, occurrence and toxicological relevance. Cambridge: The Royal Society of Chemistry; 2016. p. 1-13. doi: 10.1039/978178262257400001

4. Bennett JW. Mycotoxins, mycotoxicosis, mycotoxicology and Mycopathologia. Mycopathologia 1987;100:3-5. doi: 10.1007/BF00769561

5. Streit E, Naehrer K, Rodrigues I, Schatzmayr G. Mycotoxin occurrence in feed and feed raw materials worldwide: Longterm analysis with special focus on Europe and Asia. J Sci Food Agr 2013;93:2892-9. doi: 10.1002/jsfa.6225

6. Nährer K, Kovalsky P. A summary of the major threats. BIOMIN Mycotoxin Survey [displayed 12 July 2018]. Available at http://www.biomin.net/uploads/tx_news/ ART_No09_MYC_EN_0214.pdf]

7. Berthiller F, Crews C, Dall'Asta C, Saeger SD, Haesaert G, Karlovsky P, Oswald IP, Seefelder W, Speijers G, Stroka J. Masked mycotoxins: A review. Mol Nutr Food Res 2013;57:165-86. doi: 10.1002/mnfr.201100764

8. Commission Regulation (EC) No 1881/2006 of 19 December 2006 setting maximum levels for certain contaminants in foodstuffs setting maximum levels certain contamination foodstuffs [displayed 12 July 2018]. Available at http://eurlex . e uropa.eu/legal - content/EN/T X T / $\mathrm{PDF} /$ ?uri=CELEX:32006R1881\&from=EN

9. 2013/165/EU: Commission Recommendation of 27 March 2013 on the presence of T-2 and HT-2 toxin in cereals and cereal products Text with EEA relevance [displayed 12 July 2018]. Available at https://eur-lex.europa.eu/legal-content/ EN/TXT/PDF/?uri=CELEX:32013H0165\&from=EN

10. Van Egmond HP, Schothorst RC, Jonker MA. Regulations relating to mycotoxins in food perspectives in a global and European context. Anal Bioanal Chem 2007;389:147-57. doi: 10.1007/s00216-007-1317-9

11. Broekaert N, Devreese M, De Baere S, De Backer P, Croubels S. Modified Fusarium mycotoxins unmasked: From occurrence in cereals to animal and human excretion. Food Chem Toxicol 2015;80:17-31. doi: 10.1016/j.fct.2015.02.015

12. Rychlik M, Humpf H-U, Marko D, Dänicke S, Mally A, Berthiller F, Klaffke H, Lorenz N. Proposal of a comprehensive definition of modified and other forms of mycotoxins including "masked" mycotoxins. Mycotoxin Res 2014;30:197-205. doi: 10.1007/s12550-014-0203-5

13. EFSA Panel on Contaminants in the Food Chain. Scientific opinion on the risks for human and animal health related to the presence of modified forms of certain mycotoxins in food and feed. EFSA J 2014;12(12):3916. doi: 10.2903/j. efsa.2014.3916

14. Binder SB, Schwartz-Zimmermann HE, Varga E, Bichl G, Michlmayr H, Adam G, Berthiller F. Metabolism of zearalenone and its major modified forms in pigs. Toxins 2017;9:56. doi: 10.3390/toxins9020056
15. Schneweis I, Meyer K, Engelhardt G, Bauer J. Occurrence of zearalenone-4- $\beta$-D-glucopyranoside in wheat. J Agr Food Chem 2002;50:1736-8. doi: 10.1021/jf010802t

16. Berthiller F, Dall'Asta C, Schuhmacher R, Lemmens M, Adam G, Krska R. Masked mycotoxins: determination of a deoxynivalenol glucoside in artificially and naturally contaminated wheat by liquid chromatography-tandem mass spectrometry. J Agr Food Chem 2005;53:3421-5. doi: 10.1021/jf047798g

17. Generotti S, Cirlini M, Šarkanj B, Sulyok M, Berthiller F, Dall'Asta C, Suman M. Formulation and processing factors affecting trichothecene mycotoxins within industrial biscuitmaking. Food Chem 2017;229:597-603. doi: 10.1016/j. foodchem.2017.02.115

18. Di Mavungu JD, De Saeger S. Masked mycotoxins in food and feed: challenges and analytical approaches. In: De Saeger $\mathrm{S}$, editor. Determining mycotoxins and mycotoxigenic fungi in food feed. Cambridge: Woodhead Publishing Ltd; 2011; p. 385-400. doi: 10.1533/9780857090973.5.387

19. Kluger B, Bueschl C, Lemmens M, Michlmayr H, Malachova A, Koutnik A, Maloku I, Berthiller F, Adam G, Krska R, Schuhmacher R. Biotransformation of the mycotoxin deoxynivalenol in Fusarium resistant and susceptible near isogenic wheat lines. PLoS One 2015;10(3):e0119656. doi: 10.1371/journal.pone. 0119656

20. Warth B, Fruhmann P, Wiesenberger G, Kluger B, Sarkanj B, Lemmens M, Hametner C, Fröhlich J, Adam G, Krska R, Schuhmacher R. Deoxynivalenol-sulfates: identification and quantification of novel conjugated (masked) mycotoxins in wheat. Anal Bioanal Chem 2015;407:1033-9. doi: 10.1007/ s00216-014-8340-4

21. Warth B, Favero G Del, Wiesenberger G, Puntscher H, Woelflingseder L, Fruhmann P, Sarkanj B, Krska R, Schuhmacher R, Adam G, Marko D. Identification of a novel human deoxynivalenol metabolite enhancing proliferation of intestinal and urinary bladder cells. Sci Rep-UK 2016;6:33954. doi: 10.1038/srep33854

22. Stanic A, Uhlig S, Sandvik M, Rise F, Wilkins AL, Miles CO. Characterization of deoxynivalenol-glutathione conjugates using nuclear magnetic resonance spectroscopy and liquid chromatography-high-resolution mass spectrometry. J Agr Food Chem 2016;64:6903-10. doi: 10.1021/acs.jafc.6b02853

23. Uhlig S, Stanic A, Hofgaard IS, Kluger B, Schuhmacher R, Miles CO. Glutathione-conjugates of deoxynivalenol in naturally contaminated grain are primarily linked via the epoxide group. Toxins 2016;8:329. doi: 10.3390/ toxins8110329

24. Dellafiora L, Dall'Asta C. Masked mycotoxins: An emerging issue that makes renegotiable what is ordinary. Food Chem 2016;213:534-5. doi: 10.1016/j.foodchem.2016.06.112

25. European Food Safety Authority (EFSA). Deoxynivalenol in food and feed: occurrence and exposure. EFSA J 2013;11:3379-434. doi: 10.2903/j.efsa.2013.3379

26. European Food Safety Authority (EFSA). Appropriateness to set a group health-based guidance value for zearalenone and its modified forms. Panel on Contaminants in the Food Chain (CONTAM). EFSA J 2016;14:4425. doi: 10.2903/j. efsa.2016.4425

27. Lattanzio VMT, Visconti A, Haidukowski M, Pascale M. Identification and characterization of new Fusarium masked 
mycotoxins, T2 and HT2 glycosyl derivatives, in naturally contaminated wheat and oats by liquid chromatography-highresolution mass spectrometry. J Mass Spectrom 2012;47:46675. doi: $10.1002 / \mathrm{jms} .2980$

28. Nakagawa H, Ohmichi K, Sakamoto S, Sago Y, Kushiro M, Nagashima H, Yoshida M, Nakajima T. Detection of a new Fusarium masked mycotoxin in wheat grain by highresolution LC-Orbitrap ${ }^{\mathrm{TM}}$ MS. Food Addit Contam A 2011;28:1447-56. doi: 10.1080/19440049.2011.597434

29. Nakagawa H, Sakamoto S, Sago Y, Kushiro M, Nagashima $\mathrm{H}$. Detection of masked mycotoxins derived from type A trichothecenes in corn by high-resolution LC-Orbitrap mass spectrometer. Food Addit Contam A 2013;30:1407-14. doi: 10.1080/19440049.2013.790087

30. Zachariasova M, Vaclavikova M, Lacina O, Vaclavik L, Hajslova J. Deoxynivalenol oligoglycosides: new "masked" Fusarium toxins occurring in malt, beer, and breadstuff. J Agr Food Chem 2012;60:9280-91. doi: 10.1021/jf302069z

31. Nakagawa H. Research on mycotoxin glucosides (masked mycotoxins). JSM Mycotoxins 2016;66:21-5. doi: 10.2520/ myco.66.21

32. Lemmens M, Steiner B, Sulyok M, Nicholson P, Mesterhazy A, Buerstmayr H. Masked mycotoxins: does breeding for enhanced Fusarium head blight resistance result in more deoxynivalenol-3-glucoside in new wheat varieties? World Mycotoxin J 2016;9:741-54. doi: 10.3920/WMJ2015.2029

33. Soukup ST, Kohn BN, Pfeiffer E, Geisen R, Metzler M, Bunzel M, Kulling SE. Sulfoglucosides as novel modified forms of the mycotoxins alternariol and alternariol monomethyl ether. JAgr Food Chem 2016;64:8892-901. doi: 10.1021/acs.jafc.6b03120

34. Alexander NJ, McCormick SP, Waalwijk C, Van Der Lee T, Proctor RH. The genetic basis for 3-AC-DON and 15-ACDON trichothecene chemotypes in Fusarium. Fungal Genet Biol 2011;48:485-95. doi: 10.1016/j.fgb.2011.01.003

35. Yoshizawa T, Morooka N. Biological modification of trichothecene mycotoxins: acetylation and deacetylation of deoxynivalenols by Fusarium spp. Appl Microbiol 1975;29:54-8. PMCID: PMC186910

36. Prelusky DB, Veira DM, Trenholm HL, Foster BC. Metabolic fate and elimination in milk, urine and bile of deoxynivalenol following administration to the lactating sheep. J Env Sci Health 1987;22:125-48. PMID: 3584838

37. European Food Safety Authority (EFSA). Opinion of the Scientific Panel on Contaminants in the Food Chain on a request from the Commission (CONTAM) related to Zearalenone as undesirable substance in animal feed. EFSA J 2004;89:1-35. doi: 10.2903/j.efsa.2004.89

38. Mirocha CJ, Pathre SV, Robison TS. Comparative metabolism of zearalenone and transmission into bovine milk. Food Cosmet Toxicol 1981;19:25-30. doi: 10.1016/0015-6264(81)90299-6

39. Olsen M, Mirocha CJ, Abbas HK, Johansson B. Metabolism of high concentrations of dietary zearalenone by young male turkey poults. Poultry Sci 1986;65:1905-10. doi: 10.3382/ ps.0651905

40. Šarkanj B, Warth B, Uhlig S, Abia WA, Sulyok M, Klapec $\mathrm{T}$, et al. Urinary analysis reveals high deoxynivalenol exposure in pregnant women from Croatia. Food Chem Toxicol 2013;62:231-7. doi: 10.1016/j.fct.2013.08.043
41. Meky FA, Turner PC, Ashcroft AE, Miller JD, Qiao YL, Roth MJ, Wild CP. Development of a urinary biomarker of human exposure to deoxynivalenol. Food Chem Toxicol 2003;41:26573. doi: 10.1016/S0278-6915(02)00228-4

42. Warth B, Sulyok M, Berthiller F, Schuhmacher R, Krska R. New insights into the human metabolism of the Fusarium mycotoxins deoxynivalenol and zearalenone. Toxicol Lett 2013;220:88-94. doi: 10.1016/j.toxlet.2013.04.012

43. Maul R, Warth B, Kant J-S, Schebb NH, Krska R, Koch M, Sulyok M. Investigation of the hepatic glucuronidation pattern of the Fusarium mycotoxin deoxynivalenol in various species. Chem Res Toxicol 2012;25:2715-7. doi: 10.1021/ tx300348x

44. De Boevre M, Njumbe Ediage E, Van Pouckea C, De Saeger S. Chapter 4: Untargeted analysis of modified mycotoxins using high-resolution mass spectrometry. In: Dall'Asta C, Berthiller F, editors. Masked mycotoxins in food - formation, occurrence and toxicological relevance. Cambridge: The Royal Society of Chemistry; 2016. p. 50-72. doi: 10.1039/9781782622574-00050

45. Klapec T, Šarkanj B, Banjari I, Strelec I. Urinary ochratoxin $\mathrm{A}$ and ochratoxin alpha in pregnant women. Food Chem Toxicol 2012; 50:4487-92. https://doi.org/10.1016/j. fct.2012.09.030

46. Suman M, Generotti S. Chapter 5: Transformation of mycotoxins upon food processing: Masking, binding and degradation phenomena. In: Dall'Asta C, Berthiller F, editors. Masked mycotoxins in food - formation, occurrence and toxicological relevance. Cambridge: The Royal Society of Chemistry; 2016. p. 73-96. doi: 10.1039/978178262257400073

47. Bittner A, Cramer B, Humpf H-U. Matrix binding of ochratoxin A during roasting. J Agr Food Chem 2013;61:12737-43. doi: 10.1021/jf403984x

48. Crews C, Jane S, Donald MAC. Chapter 2: Natural Occurrence of Masked Mycotoxins. In: Dall'Asta C, Berthiller F, editors. Masked mycotoxins in food - formation, occurrence and toxicological relevance. Cambridge: The Royal Society of Chemistry; 2016. p. 14-31. doi: 10.1039/9781782622574-00014

49. Humpf HU, Voss KA. Effects of thermal food processing on the chemical structure and toxicity of fumonisin mycotoxins. Mol Nutr Food Res 2004;48:255-69. doi: 10.1002/ mnfr.200400033

50. Dall'Asta C, Battilani P. Fumonisins and their modified forms, a matter of concern in future scenario? World Mycotoxin J 2016;9:727-39. doi: 10.3920/WMJ2016.2058

51. Howard PC, Churchwell MI, Couch LH, Marques MM, Doerge DR. Formation of $N$-(carboxymethyl)fumonisin $\mathrm{B}_{1}$, following the reaction of fumonisin $B_{1}$ with reducing sugars. J Agr Food Chem 1998;46:3546-57. doi: 10.1021/jf980194q

52. Seefelder W, Hartl M, Humpf H-U. Determination of $\mathrm{N}$-(carboxymethyl)fumonisin $\mathrm{B}_{1}$ in corn products by liquid chromatography/electrospray ionization-mass spectrometry. J Agr Food Chem 2001;49:2146-51. doi: 10.1021/jf001429c

53. Hartl M, Humpf HU. Toxicity assessment of fumonisins using the brine shrimp (Artemia salina) bioassay. Food Chem Toxicol 2000;38:1097-102. doi: 10.1016/S02786915(00)00112-5

54. Bryła M, Roszko M, Szymczyk K, Jędrzejczak R, Obiedziński MW. Fumonisins and their masked forms in 
maize products. Food Control 2016;59:619-27. doi: 10.1016/j.foodcont.2015.06.032

55. Voss K, Ryu D, Jackson L, Riley R, Gelineau-Van Waes J. Reduction of fumonisin toxicity by extrusion and nixtamalization (Alkaline Cooking). J Agr Food Chem 2017;65:7088-96. doi: 10.1021/acs.jafc.6b05761

56. Bryła M, Waśkiewicz A, Szymczyk K, Jędrzejczak R. Effects of $\mathrm{pH}$ and temperature on the stability of fumonisins in maize products. Toxins 2017;9:88. doi: 10.3390/toxins 9030088

57. Bryła M, Roszko M, Szymczyk K, Jędrzejczak R, Bieta Słowik E, Obiedzinki MW. Effect of baking on reduction of free and hidden fumonisins in gluten-free bread. J Agr Food Chem 2014;62:10341-7. doi: 10.1021/jf504077m

58. Dall'Asta C, Mangia M, Berthiller F, Molinelli A, Sulyok M, Schuhmacher R, Krska R, Galaverna G, Dossena A, Marchelli R. Difficulties in fumonisin determination: the issue of hidden fumonisins. Anal Bioanal Chem 2009;395:1335-45. doi: 10.1007/s00216-009-2933-3

59. Falavigna C, Cinirni M, Galaverna G, Dall'Asta C. Masked fumonisins in processed food: co-occurrence of hidden and bound forms and their stability under digestive conditions. World Mycotoxin J 2012;5:325-34. doi: 10.3920/ WMJ2012.1403

60. Scott PM. Recent research on fumonisins: a review. Food Addit Contam A 2012;29:242-8. doi: 10.1080/19440049.2010.546000

61. Vidal A, Morales H, Sanchis V, Ramos AJ, Marín S. Stability of DON and OTA during the breadmaking process and determination of process and performance criteria. Food Control 2014;40:234-42. doi: 10.1016/j.foodcont.2013.11.044

62. Simsek S, Burgess K, Whitney KL, Gu Y, Qian SY. Analysis of deoxynivalenol and deoxynivalenol-3-glucoside in wheat. Food Control 2012;26:287-92. doi: 10.1016/j. foodcont.2012.01.056

63. Kostelanska M, Dzuman Z, Malachova A, Skerikova A, Hajslova J. Effects of milling and baking technologies on levels of deoxynivalenol and its masked form deoxynivalenol3-glucoside. J Agr Food Chem 2011;59:9303-12. doi: $10.1021 / \mathrm{jf202428 \textrm {f }}$

64. Kostelanska M, Hajslova J, Zachariasova M, Malachova A, Kalachova K, Poustka J, Fiala J, Scott PM, Berthiller F, Krska R. Occurrence of deoxynivalenol and its major conjugate, deoxynivalenol-3-glucoside, in beer and some brewing intermediates. J Agr Food Chem 2009;57:3187-94. doi: $10.1021 / \mathrm{jf} 803749 \mathrm{u}$

65. Lancova K, Hajslova J, Poustka J, Krplova A, Zachariasova M, Dostalek P, Sachambula L. Transfer of Fusarium mycotoxins and "masked" deoxynivalenol (deoxynivalenol3-glucoside) from field barley through malt to beer. Food Addit Contam A 2008;25:732-44. doi: 10.1080/02652030701779625

66. Varga E, Malachova A, Schwartz H, Krska R, Berthiller F. Survey of deoxynivalenol and its conjugates deoxynivalenol3 -glucoside and 3-acetyl- deoxynivalenol in 374 beer samples. Food Addit Contam A 2013;30:137-46. doi: 10.1080/19440049.2012.726745

67. Karlovsky P, Suman M, Berthiller F, De Meester J, Eisenbrand G, Perrin I, Oswald IP, Speijers G, Chiodini A, Recker T, Dussor P. Impact of food processing and detoxification treatments on mycotoxin contamination.
Mycotoxin Res 2016;32:179-205. doi: 10.1007/s12550-0160257-7

68. Malachova A, Dzuman Z, Veprikova Z, Vaclavikova M, Zachariasova M, Hajslova J. Deoxynivalenol, deoxynivalenol3-glucoside, and enniatins: the major mycotoxins found in cereal-based products on the Czech market. J Agr Food Chem 2011;59:12990-7. doi: 10.1021/jf203391x

69. De Boevre M, Di Mavungu JD, Maene P, Audenaert K, Deforce D, Haesaert G, Eeckhout M, Callebaut A, Berthiller F, Van Peteghem C, De Saeger S. Development and validation of an LC-MS/MS method for the simultaneous determination of deoxynivalenol, zearalenone, T-2-toxin and some masked metabolites in different cereals and cereal-derived food. Food Addit Contam A 2012;29:819-35. doi: 10.1080/19440049.2012.656707

70. Šarkanj B, Varga E, Habschied K, Krstanović V, Sakač N. Preliminarno praćenje pojavnosti mikotoksina u kukuruzu na području kontinentalne Hrvatske [Preliminarily research on the occurrence of mycotoxins in maize samples in continental Croatia, in Croatian]. In: Stipišević B, Sorić R, editors. Proceedings \& abstracts of $5^{\text {th }}$ international scientific/ professional conference Agriculture in nature and environment protection; 4-6 June 2012. Vukovar, Croatia. Osijek: Glas Slavonije d.d.; 2012. p. 264-9.

71. Zachariasova M, Hajslova J, Kostelanska M, Poustka J, Krplova A, Cuhra P, Hochel I. Deoxynivalenol and its conjugates in beer: A critical assessment of data obtained by enzyme-linked immunosorbent assay and liquid chromatography coupled to tandem mass spectrometry. Anal Chim Acta 2008;625:77-86. doi: 10.1016/j.aca.2008.07.014

72. Gonçalves C, Stroka J. Cross-reactivity features of deoxynivalenol (DON)-targeted immunoaffinity columns aiming to achieve simultaneous analysis of DON and major conjugates in cereal samples. Food Addit Contam A 2016;33:1053-62. doi: 10.1080/19440049.2016.1188436

73. Sulyok M, Berthiller F, Krska R, Schuhmacher R. Development and validation of a liquid chromatography/ tandem mass spectrometric method for the determination of 39 mycotoxins in wheat and maize. Rapid Commun Mass Sp 2006;20:2649-59. doi: 10.1002/rcm.2640

74. Jackson LC, Kudupoje MB, Yiannikouris A. Simultaneous multiple mycotoxin quantification in feed samples using three isotopically labeled internal standards applied for isotopic dilution and data normalization through ultra-performance liquid chromatography/electrospray ionization tandem mass spectrometry. Rapid Commun Mass Sp 2012;26:2697-713. doi: $10.1002 / \mathrm{rcm} .6405$

75. Malachová A, Sulyok M, Beltrán E, Berthiller F, Krska R. Optimization and validation of a quantitative liquid chromatography-tandem mass spectrometric method covering 295 bacterial and fungal metabolites including all regulated mycotoxins in four model food matrices. J Chromatogr A 2014;1362:145-56. doi: 10.1016/j. chroma.2014.08.037

76. Berthiller F, Berera C, Iha M, Krska R, Lattanzio V, MacDonald S, Malone RJ, Maragos C, Solfrizzo M, StranskaZachariasova M, Stroka J, Tittlemier SA. Developments in mycotoxin analysis: an update for 2015-2016. World Mycotoxin J 2017;10:5-29. doi: 10.3920/WMJ2016.2138

77. Zachariasova M, Lacina O, Malachova A, Kostelanska M, Poustka J, Godula M, Hajslova J. Novel approaches in 
analysis of Fusarium mycotoxins in cereals employing ultra performance liquid chromatography coupled with high resolution mass spectrometry. Anal Chim Acta 2010;662:5161. doi: 10.1016/j.aca.2009.12.034

78. Krska R, Sulyok M, Berthiller F, Schuhmacher R. Mycotoxin testing: from multi-toxin analysis to metabolomics. JSM Mycotoxins 2017;67:11-6. doi: 10.2520/myco.67-1-8

79. Dall'Erta A, Cirlini M, Dall'Asta M, Del Rio D, Galaverna G, Dall'Asta C. Masked mycotoxins are efficiently hydrolyzed by human colonic microbiota releasing their aglycones. Chem Res Toxicol 2013;26:305-12. doi: 10.1021/ tx300438c

80. De Boevre M, Graniczkowska K, De Saeger S. Metabolism of modified mycotoxins studied through in vitro and in vivo models: An overview. Toxicol Lett 2015;233:24-8. doi: 10.1016/j.toxlet.2014.12.011

81. Gratz SW. Do plant-bound masked mycotoxins contribute to toxicity? Toxins 2017;9:85. doi: 10.3390/toxins9030085

82. Cirlini M, Barilli A, Galaverna G, Michlmayr H, Adam G, Berthiller F, Dall'Asta C. Study on the uptake and deglycosylation of the masked forms of zearalenone in human intestinal Caco-2 cells. Food Chem Toxicol 2016;98:232-9. doi: 10.1016/j.fct.2016.11.003

83. Pierron A, Mimoun S, Murate LS, Loiseau N, Lippi Y, Bracarense APFL, Liaubet L, Schatzmayr G, Berthiller F, Moll WD, Oswald IP Intestinal toxicity of the masked mycotoxin deoxynivalenol-3- $\beta$-d-glucoside. Arch Toxicol 2016;90:2037-46. doi: 10.1007/s00204-015-1592-8

84. Dall'Asta C, Falavigna C, Galaverna G, Dossena A, Marchelli R. In vitro digestion assay for determination of hidden fumonisins in maize. J Agr Food Chem 2010;58:12042-7. doi: 10.1021/jf103799q

85. Broekaert N, Devreese M, Demeyere K, Berthiller F, Michlmayr H, Varga E, Adam G, Meyer E, Croubels S. Comparative in vitro cytotoxicity of modified deoxynivalenol on porcine intestinal epithelial cells. Food Chem Toxicol 2016;95:103-9. doi: 10.1016/j.fct.2016.06.012

86. Dellafiora L, Galaverna G, Righi F, Cozzini P, Dall'asta C. Assessing the hydrolytic fate of the masked mycotoxin zearalenone-14-glucoside - A warning light for the need to look at the "maskedome". Food Chem Toxicol 2017;99:9-16. doi: 10.1016/j.fct.2016.11.013

87. Gareis M, Bauer J, Thiem J, Plank G, Grabley S, Gedek B. Cleavage of zearalenone-glycoside, a masked mycotoxin, during digestion in swine. J Vet Med B 1990;37:236-40. doi: 10.1111/j.1439-0450.1990.tb01052.x

88. Veršilovskis A, Geys J, Huybrechts B, Goossens E, De Saeger $\mathrm{S}$, Callebaut A. Simultaneous determination of masked forms of deoxynivalenol and zearalenone after oral dosing in rats by LC-MS/MS. World Mycotoxin J 2012;5:303-18. doi: 10.3920/WMJ2012.1411

89. Nagl V, Schwartz H, Krska R, Moll W-D, Knasmüller S, Ritzmann M, Adam G, Berthiller F. Metabolism of the masked mycotoxin deoxynivalenol-3-glucoside in rats. Toxicol Lett 2012;213:367-73. doi: 10.1016/j. toxlet.2012.07.024

90. Nagl V, Woechtl B, Schwartz-Zimmermann HE, HennigPauka I, Moll W-D, Adam G, Berthiller F. Metabolism of the masked mycotoxin deoxynivalenol-3-glucoside in pigs. Toxicol Lett 2014;229:190-7. doi: 10.1016/j. toxlet.2014.06.032

91. Han Z, Tangni EK, Di Mavugnu JD, Vanhaecke L, De Saeger $\mathrm{S}, \mathrm{Wu} \mathrm{A}$, Callebaut $\mathrm{A}$. In vitro glucuronidation of ochratoxin A by rat liver microsomes. Toxins 2013;5:2671-85. doi: 10.3390/toxins5122671

92. Yoshinari T, Sakuda S, Furihata K, Furusawa H, Ohnishi T, Sugita-Konishi Y, Ishizaki N, Terajima J. Structural determination of a nivalenol glucoside and development of an analytical method for the simultaneous determination of nivalenol and deoxynivalenol, and their glucosides, in wheat. J Agric Food Chem 2014;62:1174-80. doi: 10.1021/ jf4048644

\section{Jučer maskirani, a danas modificirani - što je sljedeće s mikotoksinima?}

Mikotoksini su sekundarni metaboliti toksigenih plijesni široko rasprostranjenih u usjevima. Biljke, životinje, bakterije i plijesni posjeduju sposobnost modifikacije mikotoksina, a do nje može doći i tijekom obrade hrane, što rezultira nastankom velikog broja „maskiranih” oblika mikotoksina. Tako modificirani oblici mikotoksina često ostaju nevidljivi pri različitim analitičkim tehnikama, što utječe i na točnu procjenu rizika jer se nakon konzumacije kontaminiranih namirnica modificirani oblici mikotoksina u probavnom sustavu vraćaju u izvorni oblik. To je dovelo do potrebe za analitičkim tehnikama kojima se mogu detektirati i kvantificirati modificirani oblici mikotoksina. Sprega tekućinske kromatografije i spektrometrije masa (LC-MS/MS) analitička je tehnika detekcije koja najviše obećava, a za otkrivanje novih modificiranih spojeva uglavnom se primjenjuju spektrometri masa visoke rezolucije. Unatoč tome, toksični utjecaj modificiranih oblika mikotoksina još nije do kraja razjašnjen. 